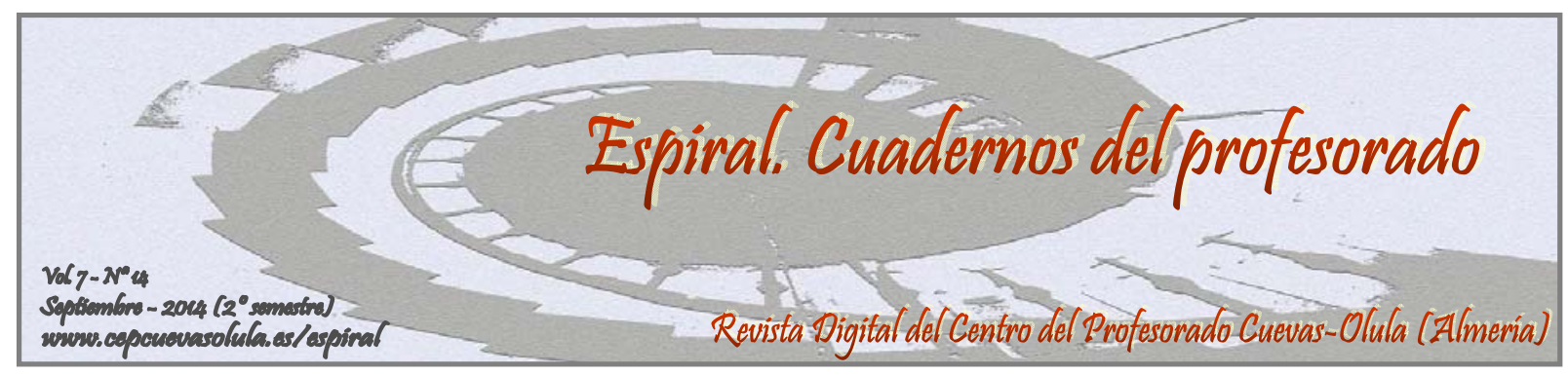

\title{
USO DIDÁCTICO DE LAS INFOGRAFÍAS
}

\section{EDUCATIONAL USE OF INFOGRAPHICS}

\author{
Esther Muñoz García
}

IES Cura Valera, Huércal-Overa, Almería, España

RESUMEN: Las Tecnologías de la Información y la Comunicación (TIC) son parte de la cotidianidad de nuestros educandos, por lo que es responsabilidad del profesorado adaptarse a este nuevo estilo de comunicación, a fin de captar la atención del alumnado, motivarle e incitarle al aprendizaje. El presente trabajo pretende dar a conocer y promover el uso de la infografía didáctica entre el profesorado como novedosa forma de transmitir la información. La infografía ha sido y sigue siendo uno de los medios más importantes que poseen los periódicos y revistas para transmitir la información de forma clara, asequible y precisa, mediante textos, imágenes, mapas, gráficos y todo tipo de iconos, pero con la aparición de diferentes alternativas de software gratuitas on-line, cualquier usuario de a pie puede crear una infografía de forma rápida, sencilla y de aspecto profesional. Esto ha permitido exportar las ventajas de la infografía a otros ámbitos, entre ellos el educativo. Se darán además unas nociones básicas a profesores iniciados en el uso de infografías sobre la forma de crear su propio material infográfico. Por último, se determinará en qué medida, las infografías son una forma valiosa de trasmitir la información y acercar el alumnado al conocimiento.

Palabras clave: enseñanza-aprendizaje, conocimiento visual, recurso educativo

ABSTRACT: the Information Technology and Communication (TIC) are part of the daily lives of our students, so it is the responsibility of teachers to adapt to this new style of communication, in order to capture the attention of students, motivate learning and encourage it. This article seeks to highlight and promote the use of infographics teaching among teachers as a novel way of conveying information. Infographics has been and remains one of the most important ways that newspapers and magazines have to convey information in a clear, accurate and affordable through texts, images, maps, graphs and all kinds of icons, but with the emergence of alternatives free on-line software, any ordinary user can create an infographic for a quick, easy and professional looking. This advantage has allowed export of infographics to other areas, including education. They also give teachers basic initiated into the use of infographics on how to create your own infographic item notions. Finally, determine to what extent computer graphics are a valuable way to convey information and bringing knowledge to students

Key words: teaching - learning, visual knowledge, educational resource

Muñoz García, E. (2014). Uso didáctico de las infografías. Espiral. Cuadernos del Profesorado, 7(14), 37-43. Disponible en: http://www.cepcuevasolula.es/espiral.

Fecha de recepción: 14/03/2014

Fecha de aceptación: 25/06/2014
Enviar correspondencia a: esthermg@andaluciajunta.es 


\section{1.- INTRODUCCIÓN}

El profesorado en general, y más especialmente el que imparte enseñanzas en Educación Secundaria Obligatoria, se encuentra a diario con la dificultad para captar la atención del alumnado, así como para motivarle e incitarle al aprendizaje.

Si algo aporta las nuevas tecnologías al trabajo del profesorado en las aulas, es la posibilidad de presentar y transmitir con mayor facilidad el elemento didáctico.

"Si el educador no hace un esfuerzo por asumir este nuevo estilo de comunicación ${ }^{1}$... permanecerá recluido en un mundo distinto y alejado de los verdaderos problemas de sus educandos" (Santos, 1984, p. 30).

Habitualmente cuando se nos presenta una información, ya sea periodística o de tipo didáctico, primero leemos los titulares, posteriormente observamos las imágenes y después prestamos atención al texto. A esto hace referencia Richard Curtis, director de fotografía y diseño del diario USA Today, "La gente lee primero los gráficos y algunas veces es la única cosa que lee" (Curtis, 1991).

"Una infografía es una combinación de elementos visuales que aporta un despliegue gráfico de la información. Se utiliza fundamentalmente para brindar una información compleja mediante una presentación gráfica que puede sintetizar o esclarecer o hacer más atractiva su lectura" (Clarins, 1997, p.125).

Las infografías son usadas habitualmente en el ámbito periodístico, sin embargo, con las infografías podemos narrar historias, explicar acontecimientos, describir situaciones, exponer procesos, etc., por lo que su uso se está comenzando a extender a otros ámbitos, entre ellos, el educativo, permitiendo hacer una exposición llamativa y novedosa, capaz de captar la atención del alumnado, y que asimilen más eficazmente unos contenidos con un "golpe de vista".

Para Rosana Larranz ”son más sintéticas que los vídeos, más narrativas que un esquema, más atractivas que las tablas de datos, más exploratorias que las presentaciones tradicionales y, a diferencia de los textos escritos, permiten visualizar la información que presentan” (Larranz, 2010).

Desde tiempos históricos, muy anterior, naturalmente, a la presencia de la informática, el hombre ha usado técnicas comunicativas pictóricas como forma de simplificar sus mensajes para hacerlos fáciles de comprender, recordar y compartir.

Aunque parezca que este formato gráfico es reciente, se ha encontrado en numerosas manifestaciones culturales de la humanidad.

"Como vehículo del pensamiento, lo visual es anterior a cualquier lenguaje en la historia de las comunicaciones entre los hombres. $Y$ en la historia de cada hombre en particular es también anterior a los sistemas lingüísticos que se comienzan a aprender, en los países occidentales, al empezar la educación primaria, alrededor de los seis años" (Peltzer, 1991, p.99).

Cuando hablamos del origen de la infografía no podemos determinar una fecha exacta, aunque sí encontramos sus raíces en los jeroglíficos utilizados en el antiguo Egipto, pues mostraban gráficamente la religión, hábitos, vida y trabajo de los hombres de aquella época.

Durante la Edad Media aparecen los primeros manuscritos con muchas ilustraciones para explicar el conte-

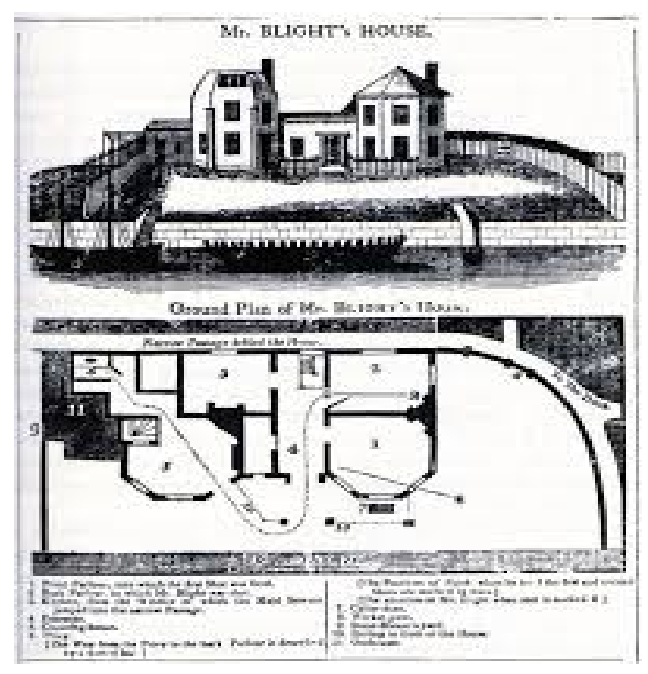

Figura 1. Primera representación infográfica en prensa

${ }^{1}$ Hace referencia a la comunicación audiovisual 
nido del mismo a analfabetos, así como los primeros organigramas (aunque muy rudimentarios) y los primeros mapas cartográficos. En el Renacimiento se realizaron enormes avances gracias a Leonardo Da Vinci y Nicolás Copérnico, quienes dejaron plasmado en papel sus investigaciones con gráficos y textos, un formato muy infográfico.

El 7 de mayo de 1806, el periódico londinense The Times publica la considerada por los expertos como la primera representación infográfica en prensa (Figura 1), que mostraba un gráfico explicativo sobre un asesinato (Valero, 2001). ${ }^{2}$

La aparición y uso de las nuevas tecnologías, a finales del siglo XX, da lugar a la aparición de la infografía digital (Figura 2), que cambia los procesos de creación, difusión y ámbitos de aplicación.

Hasta hace poco, la elaboración de infografías estaba únicamente al alcance de expertos diseñadores gráficos capaces de manejar potentes pero complejas herramientas de diseño. Actualmente, con la aparición de diferentes alternativas de software gratuitas on-line, cualquier usuario puede crear una infografía de forma rápida, sencilla y de aspecto profesional. Esto ha permitido en poco tiempo exportar las ventajas de las infografías a otros ámbitos de aplicación.

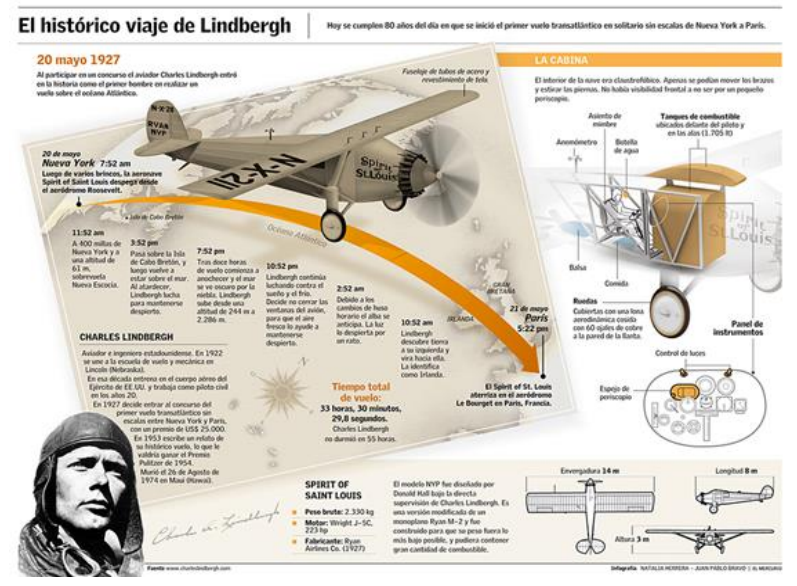

Figura 2. Ejemplo de infografía digital

Tal es el caso de la empresa, cuyos directivos están comenzando a sustituir los documentos y balances repletos de datos difíciles de digerir por sus empleados, por documentos infográficos.

Dentro de la empresa, las infografías son usadas en diversos departamentos de la misma con distintas aplicaciones (mostrar la evolución de ventas de un producto, resultados de balances financieros, recomendaciones de higiene y seguridad, memoria medioambiental de la compañía...); así como para fomentar la reputación y notoriedad de la marca entre sus clientes (especificaciones técnicas de un producto, instrucciones de utilización, recomendaciones de uso o manejo, etc.).

Dentro del ámbito arquitectónico e industrial se está extendiendo su uso para la presentación de proyectos, con la finalidad de mostrar a clientes o inversores las particularidades de cada proyecto, ventajas y beneficios, justificando así el coste o presupuesto que implica llevarlos a cabo. Del mismo modo, también es usado como medio para la promoción y venta dirigida hacia el cliente o consumidor final.

Su uso en el ámbito educativo es todavía reciente y muy novedoso, y presenta dos vertientes, por un lado su empleo en el aula como forma de presentar la información y atraer la atención del alumnado; y por otro, acercar al alumno a su elaboración y de esta forma desarrollar en él las habilidades para buscar, obtener y procesar la información, o dicho de otro modo, desarrollar la competencia digital y tratamiento de la información.

A día de hoy nadie duda su validez en el ámbito educativo. En este sentido, son algunos los estudios que avalan el provecho de este tipo de comunicación.

En el año 2009 la Universidad Autónoma de Barcelona les presenta a 15 universitarios ocho temáticas variadas usando infografías, y a pesar del alto conocimiento previo de los estudiantes, la infografía incrementa su conocimiento en un 86\% (Valero, 2009).

Investigación similar la que lleva a cabo la Universidad Nacional de Córdoba (Argentina). Trabajó con dos grupos de alumnos de entre 13 y 14 años pertenecientes a colegios distintos: a ambos grupos se le presentó una temática compleja (relacionada con la genética); a uno de ellos a través de la implementación de un CD de infografías interactivas y a otro con la ausencia de esta herramienta.

${ }^{2}$ No debe confundirse infografía con ilustración. Las ilustraciones son anteriores a este período. 
La respuesta de los alumnos a la pregunta sobre “¿qué les pareció el CD?” fueron muy positivas y la mayoría expresó que les resultaba "muy bueno para aprender” (Minervini, 2005)

A partir de las reflexiones que hemos sacado como fruto de la recopilación y análisis de información, los objetivos planteados son los siguientes:

- Dar a conocer y promover el uso de las infografías entre el profesorado, ya sea como método de presentación y transmisión de los elementos didácticos; o como forma de desarrollar la competencia digital y tratamiento de la información.

- Dar unas nociones básicas a profesores iniciados en el uso de infografías sobre cómo efectuar un correcto diseño y creación de su propio material infográfico.

- Determinar en qué medida, las infografías son una forma valiosa de trasmitir la información y acercar al alumnado al conocimiento.

\section{2.- DISEÑO Y GENERACIÓN DE INFOGRAFÍAS}

Antes de comenzar con la parte técnica, se debe realizar un minucioso diseño que incluya: planteamiento de la temática, recopilación y estructuración de la información, y elaboración de un esbozo.

1) Planteamiento de la temática. Se debe decidir la temática sobre la cual se quiere transmitir la información.

2) Recopilación de datos. A través de una investigación primaria (encuestas) o secundaria (información ya elaborada) debemos obtener y filtrar la información que emplearemos para elaborar la infografía.

3) Estructuración de la información. Validada la información se debe elaborar un esquema sobre los apartados a incluir de la manera más coherente y ordenada posible. La información deberá estructurarse de acuerdo a unos criterios lógicos, cronológicos, etc. Se debe pensar a qué tipo de personas va dirigida la infografía y adapta el nivel de dificultad.

4) Elaboración de un esbozo. Incluiremos los elementos de texto, gráficos, signos, imágenes, etc. que creamos necesarios para presentar nuestra información.(Vallejo, 2013)

a) Elección de la combinación de colores más adecuada. Debe favorecer la lectura (letras de color oscuro sobre fondo claro o viceversa).

b) No incluir demasiado texto. Selección de fuentes tipográficas fácilmente legibles.

c) Selección de gráficos e imágenes relevantes, de tamaño proporcionado y que sean fácilmente legibles (no deben estar pixelados).

d) Organización de la información a través de las relaciones establecidas previamente.

e) Por último, debemos pensar qué tipo de infografía queremos crear (informativa, cronológica, relatos de hechos históricos, estadística o mapas). (Domínguez, Robles, y Chavarrías, 2011)

Elegido el borrador se procederá a su creación. Esta parte puede resultar la más tediosa, sin embargo, con la aparición de numerosas herramientas gratuitas de software online su creación será sencilla y rápida. (Vallejo, 2013)

Algunas de estas herramientas son Pick to Chart (http://piktochart.com/), Easelly (www.easel.ly), Infogr.am (http://infogr.am), o Visual.ly (http://visual.ly).

Son páginas web que incluyen un potente editor de infografías cuyo uso es altamente intuitivo. El funcionamiento de estas páginas es muy similar entre sí. Ofrecen unas bases gráficas o plantillas que el usuario puede escoger y modificar con las opciones disponibles en su editor (Figura 3). Para hacer uso del programa, el usuario debe registrarse y se dará la opción de usar el programa de forma 
Free (con un número de plantillas y funcionalidades limitadas pero suficientes para probar su potencia), o de forma Premium (Castaneda y Pineda, 2013).

Cuando se haya finalizado la infografía, se hará referencia a las fuentes de información en las que nos hemos basado y a la autoría de la misma.

\section{3.- METODOLOGÍA}

Para el desarrollo de la investigación se ha seguido el siguiente procedimiento:

$1^{\circ}$ Se crea un grupo de trabajo $^{3}$ (en adelante GT) con seis profesores de distintas especialidades, incluida la autora del artículo en calidad de coordinadora, en un centro de Educación Secundaria perteneciente a la provincia de Almería.

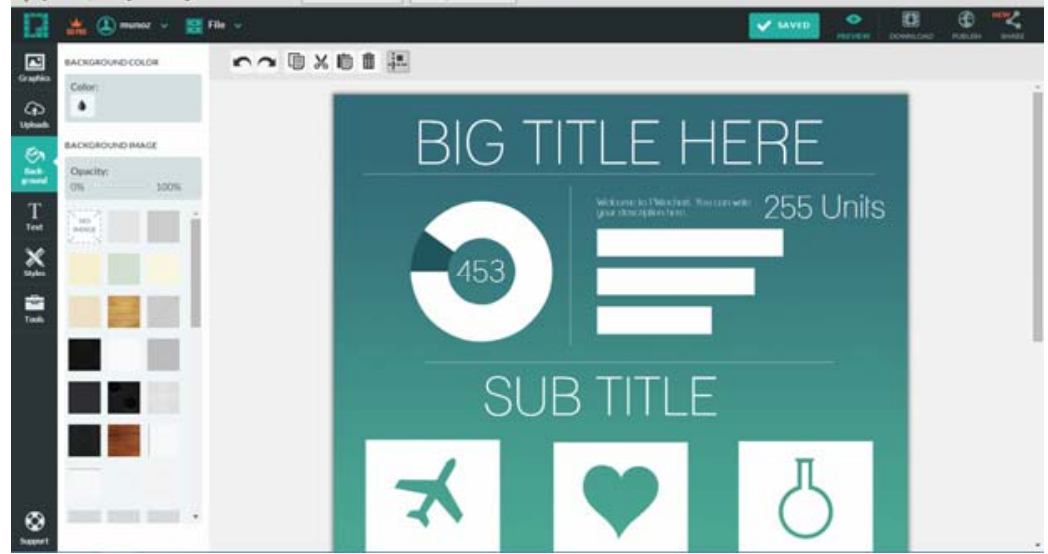

Figura 3. Editor infográfico de Pick to Chart

$2^{\circ}$ En el primer trimestre del curso escolar, la coordinadora forma al profesorado perteneciente al GT en el uso, aplicación y generación de infografías con el software Picktochart. Para ello se emplea una sesión de dos horas de duración.

$3^{\circ}$ Durante el segundo y tercer trimestre los profesores pertenecientes al GT, asesorados por la coordinadora, elaboran su propio material infográfico. La muestra final son nueve infografías (Figura 4) elaboradas por los distintos profesores que exponen diversas temáticas relacionadas con las materias impartidas (Historia, Informática, Francés, Instalaciones eléctricas, Interpretación gráfica y Operaciones de Procesos Farmaceúticos).

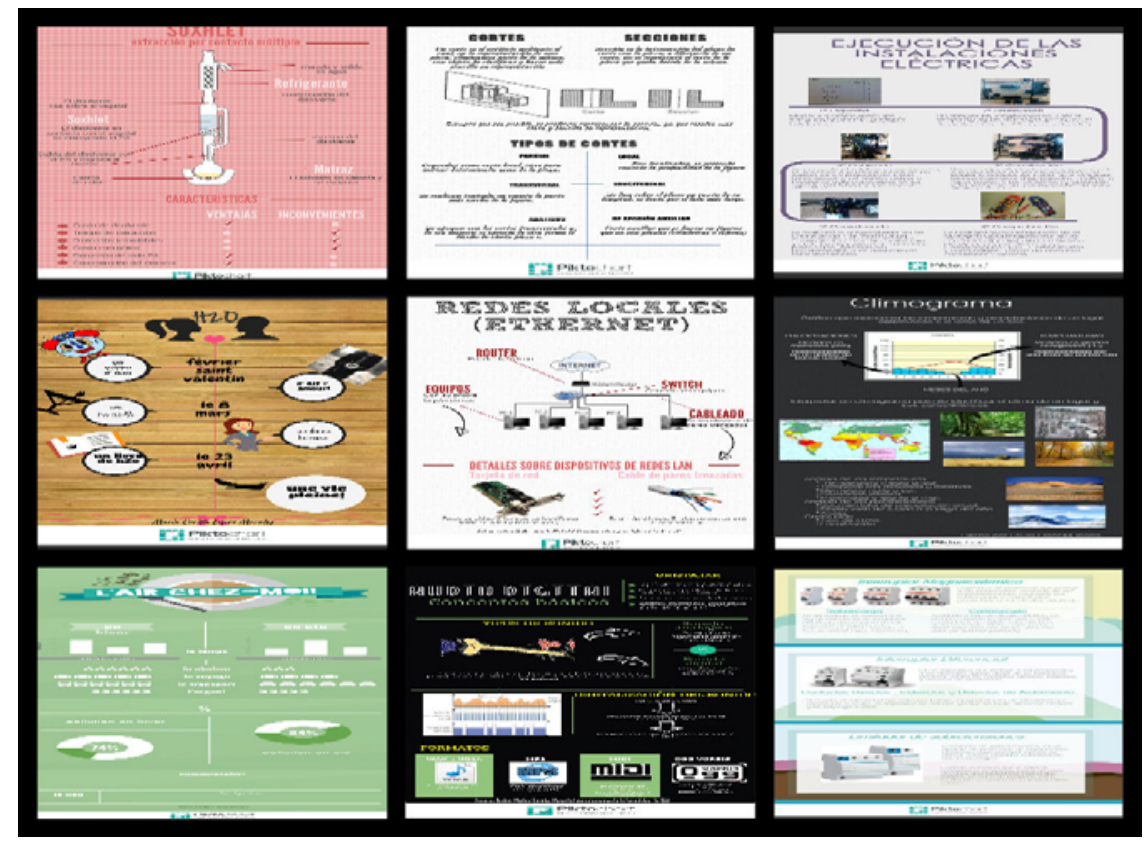

Figura 4. Material infográfico elaborado por los profesores del GT

\footnotetext{
${ }^{3}$ Los Grupos de Trabajo es una modalidad formativa, recogida en las Instrucciones de 2 de septiembre de 2013 de la Dirección General de Innovación Educativa y Formación del Profesorado, que pretende aumentar la calidad de los aprendizajes del alumnado a través de la mejora de las prácticas docentes.
} 
$5^{\circ}$ Las nueve infografías se aplican a 109 sujetos, en una sesión de una hora de duración, cuyas edades oscilan entre los 12 y 55 años y pertenecen a distintos niveles educativos (Educación Secundaria Obligatoria, Formación Profesional de grado medio y Formación Profesional Básica).

$6^{\circ}$ Las clases se desarrollan de manera específica según la metodología establecida por cada docente. Previamente se les da al alumnado unas nociones generales del concepto infografía, forma de crearlas y programas más usados para ello. No se les reveló la totalidad de las intenciones, solamente que los profesores participaban en un trabajo común para fomentar el uso de las infografías en el aula.

$7^{\circ}$ Abordada la temática, los profesores proporcionan al alumnado un cuestionario a fin de evaluar el grado de incidencia de la infografía en la adquisición de conocimientos.

$8^{\circ}$ El cuestionario consta de diez preguntas de respuesta cerrada (SI/NO), que pretende evaluar la importancia de las TIC en el aula, impresión causada de la infografía, así como el grado de utilidad de ésta para facilitar la compresión, repasar o ampliar conocimientos. También se consideró interesante obtener información sobre hábitos de estudio del alumno.

\section{4.- RESULTADOS}

Los cuestionarios proporcionaron información valiosa sobre dos temáticas distintas del panorama educativo actual: incidencia de las TIC en el aula (Figura 5) e incidencia de las infografías en la adquisición de conocimientos (Figura 6).

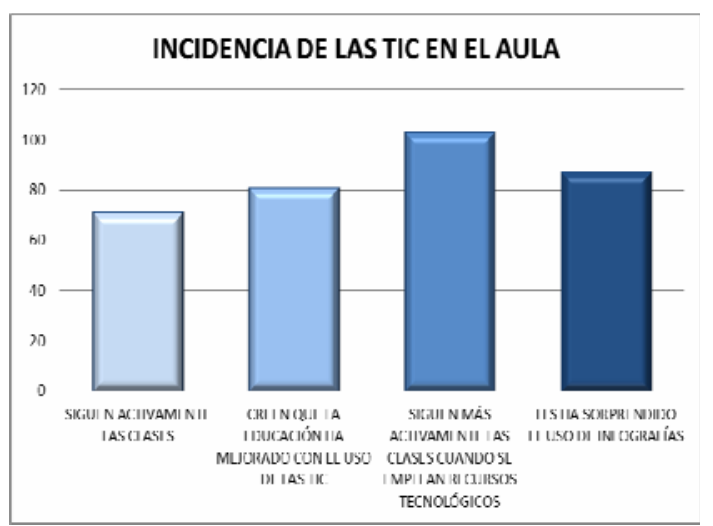

Figura 5. Incidencias de las TIC en el aula

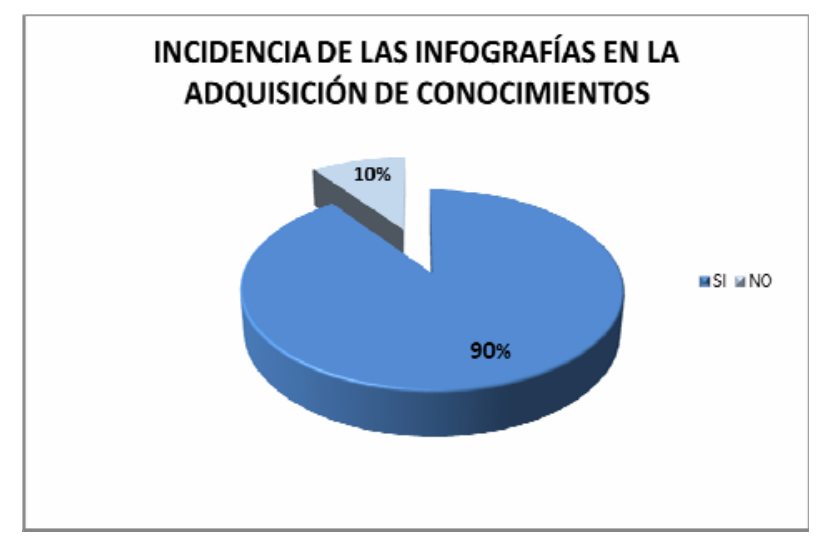

Figura 6. Incidencias de las infografías en la adquisición de conocimientos

El gráfico de la Figura 5 muestra la percepción positiva que tiene el alumnado del empleo de las TIC en educación, así como el incremento de manera significativa del interés por la temática planteada por el profesor y un mayor seguimiento de las clases cuando el profesor hace uso de recursos tecnológicos en el aula.

De los 109 alumnos encuestados, 81 (74,31\%) opina que la educación ha mejorado con el uso de las TIC, de hecho 103 alumnos (94,49\%) sigue más activamente las clases cuando el profesor hace uso de los recursos tecnológicos, frente a 71 alumnos (65,13\%) que afirman seguir habitualmente de forma activa las clases (independiente del empleo de las TIC por el profesor).

En el mismo gráfico, se aprecia el interés despertado por las infografías. La mayor parte del alumnado encuestado, esto es, 87 alumnos $(79,81 \%)$ ha considerado el uso de las infografías una forma novedosa de transmitir la información y ha impresionado su uso. Este dato resulta significativo dado que las TIC forman parte de la cotidianidad del alumnado.

El gráfico de la Figura 6, muestra en qué grado, el empleo de las infografías en el aula como recurso para transmitir la información ha sido valioso para acercar al alumno al conocimiento. En este sentido, los resultados sorprendieron por ser más positivos de lo esperado. 
De los 109 alumnos encuestados, 99 alumnos (90,82\%) afirman que de forma satisfactoria, el uso de infografías en el aula ha facilitado la adquisición, repaso o ampliación de contenidos, frente a 11 alumnos (10,09\%) para los cuales el uso de infografías ha sido intrascendente.

\section{5.- CONCLUSIONES}

El empleo de recursos tecnológicos en el aula es un condicionante que capta la atención del alumnado e incrementa de manera positiva el interés de los éstos por los contenidos impartidos y un seguimiento más activo de las clases. A pesar de la asiduidad de las TIC dentro y fuera del aula, el poder visual de las infografías ha conseguido impresionar al alumnado, así como facilitar la adquisición, repaso o ampliación de contenidos, lo cual se considera más trascendental.

Esto nos lleva a pensar que el uso de infografías tiene una repercusión positiva desde dos puntos de vista: el docente y el del alumnado.

Por un lado, al docente se le facilitará en gran medida el desarrollo de sus clases: aprenderá a elaborar útiles recursos didácticos. Estos recursos al presentarse de forma llamativa e impactante conseguirán captar la atención del alumnado, consiguiendo una mayor motivación y predisposición para el aprendizaje. Desde el punto de vista del alumnado, se le facilitará la asimilación y procesamiento de la información. Se trabajará con ellos la deconstrucción de un mensaje y la construcción de nuevos contenidos.

Tras apreciar que el empleo de infografías influye positivamente en el proceso de aprendizaje, surge la duda si el empleo de infografías de manera continuada durante un curso escolar, y no únicamente de manera aislada y experimental, tendría también una repercusión positiva en los rendimientos académicos del alumnado y por lo tanto en el grado de adquisición de las competencias básicas.Y de ser así, ¿̇sería positivo este método durante un largo período de tiempo o convendría combinar esta herramienta con las convencionales para que no perdiera efectividad? De demostrarse su efectividad durante un largo período de tiempo, ¿esa efectividad sería similar en todas las materias? Estas reflexiones plantean dudas que serían interesantes abordar en futuras investigaciones.

\section{6.- REFERENCIAS}

Castañeda, A. y Pineda, P. (2013). Herramientas online para la creación de infografías didácticas. Ikasnabar 2013 - MOOCs, PLEs y plataformas de eLearning, 269-278.

Clarín (1997). Manual de Estilo de Clarín. Buenos Aires: Argentino S.A. Clarín.

Curtis, R. (1991, 23 de Julio), tomado de la conferencia sobre el curso: Diseño gráfico y tipografía para s en periodismo, en el Poynter Institute for Media Studies, St.Petersburg, Florida.

Domínguez, J., Robles, A, y Chavarrías B. (2011). Uso didáctico de los pósteres e infografías. Avances en supervisión educativa, 15, 3-5.

Larranz, R. (2010). Infografías como recursos didácticos [en línea]. Cuaderno Intercultural. Disponible en http://www.cuadernointercultural.com/infografias-recurso-didactico/. Consulta: [2013, 14 Octubre]

Minervini, M. (2005). Las infografías interactivas en la práctica educativa de la Biología, 8(59), 5-7.

Peltzer G. (1991). Periodísmo iconográfico. Madrid: Rialp S.A.

Santos, M. A. (1984). Imagen y educación. Madrid: Anaya

Valero, J. L. (2001). La infografía: técnicas, análisis y usos periodísticos. Barcelona: Universitat Autónoma de Barcelona

Valero, J. L. (2009). La transmisión del conocimiento a través de la infografía digital. Ámbitos, Revista Andaluza de Comunicación, 18, 51-63.

Vallejo, C. (2013). Infografías y competencia digital. Disponible en http://recursostic.educacion.es/observatorio/web/es/cajon-de-sastre/38-cajon-de-sastre/1091-infografiasy-competencia-digital. Consulta: [2013, 3 Noviembre]

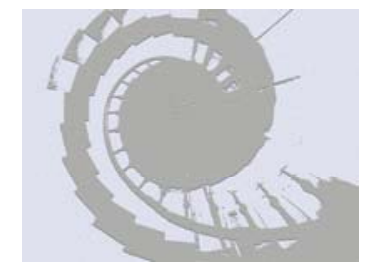

